\title{
PRIVACIDADE E COVID-19: PROTEÇÃO DO CORPO ELETRÔNICO DA PESSOA, SOB A ÓTICA DE STEFANO RODOTÀ
}

\author{
PRIVACY AND COVID-19: PROTECTION OF THE HUMAN PERSON'S \\ ELECTRONIC BODY, BY STEFANO RODOTÁ
}

Antônio Célio Martins Timbó Costa*

\begin{abstract}
Resumo
A COVID-19 tem afligido de forma brutal todo o mundo. Medidas sanitárias acabaram por atingir a incolumidade de dados sensíveis dos cidadãos. Questiona-se o papel reservado à privacidade das pessoas, especialmente quando dados sensíveis são utilizados para a formulação de políticas governamentais. $O$ trabalho pretende demonstrar, seguindo a formulação teórica de Stefano Rodotà sobre a proteção do corpo eletrônico da pessoa, que a formulação de políticas públicas não deve atingir direitos fundamentais da pessoa. Por fim, o trabalho pretende demonstrar que o dilema "direito à saúde ou direito à privacidade" encerra uma visão limitada e autoritária sobre direitos fundamentais.
\end{abstract}

\section{Palavras-chaves:}

Privacidade. Corpo Eletrônico. Covid-19. Vigilância. Proteção de Dados. Stefano Rodotà.

\begin{abstract}
COVID-19 has brutally afflicted the whole world. Sanitary measures have ended up affecting the sensitivity of citizens' sensitive data. The role reserved for the privacy is questioned, especially when sensitive data are used to formulate government policies. The work intends to demonstrate, following the theoretical formulation of Stefano Rodotà on the protection of the electronic body of the person the formulation of public policies should not achieve fundamental rights of the person. Finally, the work aims shown that the dilemma "right to health or right to privacy" contains a limited and authoritarian view on fundamental rights.
\end{abstract}

\section{Keywords:}

Privacy. Electronic Body. Covid-19. Surveillance. Data Protection. Stefano Rodotà.

\footnotetext{
* Mestrando em Processo e Direito ao Desenvolvimento pelo Centro Universitário Christus - UNICHRISTUS. Bacharel em Direito pela Universidade Federal do Ceará. Bacharel em Administração de Empresas pela Universidade Estadual do Ceará. Especialista em Direito Constitucional pela Universidade Cândido Mendes. Especialista em Direito e Processo do Trabalho pela Universidade Cândido Mendes. Especialista em Relações Humanas pela Universidade Vale do Acaraú. Juiz do Trabalho Substituto do Tribunal Regional do Trabalho da 7ạ Região. Endereço eletrônico: celiotimbo@gmail.com.
} 


\section{INTRODUÇÃO}

O autor Stephano Rodotá, em seu livro El Derecho a Tener Derechos, propõe o conceito de corpo eletrônico da pessoa humana. Para o autor italiano "En la dinámica de las relaciones sociales y también en la percepción de uno mismo, la verdadera realidad es la definida por el conjunto de las informaciones que nos afectan, organizadas electrónicamente. Este es el cuerpo que nos sitúa en el mundo“ (RODOTÀ, 2014, p. 150).

Esse conceito se faz bastante importante neste período em que o mundo vive um momento singular: uma crise epidêmica, sem precedentes na história recente, causada pelo chamado novo Coronavírus (Sars-CoV-2).

Isso porque governos de todo o mundo, sob o pálio da preservação da saúde de seus concidadãos, têm investido de forma não razoável sobre direitos de privacidade dos mesmos, malferindo o citado corpo eletrônico. Teme-se a implantação de sistemas de vigilância em massa, os quais perdurem para além do período pandêmico, em manifesta afronta ao conceito de "pessoa", também proposto por Rodotà.

É sobre isso que se pretende debruçar o presente trabalho: o embate entre direitos de personalidade - especificamente o direito à privacidade - e a vigilância imposta por governos, em regra, de natureza autoritária.

Analisar o presente tema, se constitui verdadeiro desafio, pois a apreciação dos acontecimentos está sendo feita quando os mesmos ainda estão em franco desenvolvimento, não havendo estudos mais assertivos sobre a temática.

Quer-se demonstrar que o regime democrático eleva a pessoa humana ao epicentro do ordenamento jurídico (CRFB, art. 3. $\left.{ }^{\circ}, \mathrm{I}\right)$, não havendo motivos que justifiquem o desprezo por direitos fundamentais como a privacidade, a honra, o sigilo de dados, entre outros, mesmo em tempos de crise sanitária. Ao contrário, sustenta-se que o arcabouço de direitos fundamentais deve, justamente nos períodos de crise, salvaguardar tais direitos.

Partindo de tal cenário e pressupostos, o trabalho pretende conceituar, em um primeiro momento, pessoa, corpo eletrônico e privacidade, na esteira dos ensinamentos propostos por Stefano Rodotà, mostrando as correlações entre tais conceitos.

Pretende ainda fixar o cenário social, político e econômico decorrente da pandemia, expondo os métodos telemáticos utilizados para monitoramento do contágio da doença. Buscar- 
se-á expor brevemente esse tema no contexto global, concentrando-se, após, na realidade nacional.

Estabelecidos tais parâmetros, o trabalho busca responder a seguinte questão: em que medida o uso de monitoramento telemático da pandemia, infringe o direito fundamental de privacidade da pessoa humana?

A pesquisa pretende, por fim, demonstrar que, mesmo no contexto da Covid-19, a formulação de políticas governamentais não deve, sob a justificativa do medo do contágio ou da pressa em buscar soluções para a crise sanitária, malferir direitos fundamentais da pessoa, como a privacidade dos cidadãos.

A metodologia utilizada se pautou nos seguintes aspectos: (i) pesquisa em matérias jornalísticas, dado o caráter bastante atual das questões tratadas; (ii) pesquisa bibliográfica, buscando-se, na melhor doutrina, fundamentos teóricos acerca do tema sobre investigação; e (iii) pesquisa documental, analisando-se acórdãos do Supremo Tribunal Federal sobre a problemática.

Abordar-se-á, desse modo, no capítulo 2, o conceito de pessoa humana, corpo eletrônico, privacidade, suas correlações e desdobramentos. Ademais, no capítulo 3, estudarse-á o embate entre o corpo eletrônico, o direito à privacidade e a sociedade de vigilância estabelecida, em muitos lugares, em face da Covid-19.

Por fim, o trabalho pretende jogar luzes sobre o falso dilema: opta-se pelo direito à saúde ou pela privacidade? Mostrar-se-á que esse tipo de questionamento encerra uma visão limitada sobre os direitos fundamentais, denotando ademais elevado grau de autoritarismo.

\section{CORPO ELETRÔNICO E PRIVACIDADE NA SOCIEDADE DA INFORMAÇÃO}

Vive-se, atualmente, no que se tem denominado de $4 .^{a}$ revolução industrial ou revolução 4.0. A mesma se tem caracterizado pela intensa utilização da tecnologia da informação nos processos produtivos, bem como pelo advento de uma significativa alteração nos meios de comunicação, protagonizada pela predominância das redes sociais e dos aplicativos de informática.

Como diria Rodotà, de forma poética, "retorna o conflito entre o velho e o novo mundo, um que brilha com cores de nostalgia; o outro, portador de um processo que parece querer se despedir definitivamente do humano“"(RODOTÀ, 2011, n.p). 
Nesse mesmo contexto, alguns pensadores preferem fazer referência à sociedade de informação, como tendo sido aquela que sucedeu o período pós-industrial.

Para o professor Ehrhardt Júnior, a sociedade da informação se constitui "ambiente onde a imediatividade temporal e física do acesso à informação, dado à extrema funcionalidade e celeridade dos meios tecnológicos utilizados, proporciona o que podemos denominar eliminação virtual das distâncias". No mesmo texto, apresenta como características dessa sociedade "a democratividade, isto é, o barateamento do acesso à Internet, e consequentemente, a igualização de oportunidades aos potenciais usuários, sobretudo aos hipossuficientes“ (EHRHARDT JÚNIOR; SILVA, 2010, p. 4).

Trata-se de um mundo "composto por uma submersão da coletividade no chamado ciberespaço, caracterizado por ser uma dimensão em que a comunicação é realizada na interconexão mundial dos computadores, modificando a ideia de fronteira, de liberdade e de informação" (CARVALHO; SOUSA, 2019, p. 295).

Esse contexto dá relevo aos dados pessoais do indivíduo, o que é compreensível, pois, na sociedade da informação, "somos nossos dados" (RODOTÀ, 2014, p. 150). Nessa esteira, o ex-professor de Direito Civil da universidade italiana La Sapienza enfatiza que o corpo humano já pertence “à dimensão global” e que "as informações que nos dizem respeito, e que representam nossa identidade para todos aqueles que as usam eletronicamente, estão espalhadas num número crescente de bancos de dados nos mais diversos lugares do mundo" (RODOTÀ, 2003, p. 10).

Rodotà prescreve que essa constante captura de dados pessoais pelo chamado Big Data $^{1}$ acaba tendo repercussão na formação da identidade da pessoa, que passa a ser resultado do que os outros "teclam", "visualizam" e "armazenam” a seu respeito. Esse processo, faz com o ser humano se depare "com uma identidade instável, à mercê do humor de outras pessoas, preconceitos ou interesses daqueles que coletam, mantêm ou divulgam dados pessoais", criando "uma situação de dependência que determina a construção de uma identidade 'externa' com formas que reduzem o poder de controle por parte da pessoa" (RODOTÀ, 2014, p. 163).

\footnotetext{
${ }^{1}$ Big Data é um grande volume de dados que cresce significativamente à medida que novos meios digitais são incorporados. Esses dados podem ser estruturados e incentivar o cruzamento de informações para chegar a conclusões que subsidiem decisões estratégicas de marcas ou empresas. Informação colhida no portal SITEWARE. Matéria "O que é Big Data e por que é tão valioso para sua empresa". 2019. Disponível em: https://www.siteware.com.br/gestao-estrategica/o-que-e-bigdata/. Acesso em: 28/6/2020.
} 
Sobre o tema, todo sabem de pessoas que vivem em função das publicações, comentários e "curtidas" nas redes sociais, criando um universo paralelo que, muitas vezes contribui para a erosão de seus valores pessoais e de sua própria personalidade. Infelizmente essa vida idealizada, inúmeras vezes, não corresponde aos desafios da realidade, gerando frustração e sofrimento.

Seguindo os passos de Bauman, Alexander Perazo e Raphaella Prado afirmam que "os que não podem agir de acordo com os desejos induzidos são apresentados todos os dias ao olhar deslumbrado daqueles que podem" (CARVALHO; SOUSA, 2019, p.300). Trata-se da “comodificação ${ }^{2}$ do ser humano, processo que transforma as pessoas em mercadorias de consumo.

No contexto da luta contra o terrorismo, Rodotà sintetizava suas preocupações quando à exposição desmedida de dados pessoais:

Diante de nós estão mudanças que tocam à própria antropologia das pessoas. Estamos diante de progressivos resvalos: da pessoa "perscrutada, através de câmeras de vídeo e de técnicas biométricas, pode passar-se à pessoa "modificada" mediante a inserção de chips e de etiquetas "inteligentes", em um contexto que cada vez mais claramente nos individualiza como networked persons, pessoas permanentemente em rede, configuradas de modo a emitir e receber pulsos que permitem esquadrinhar e reconstruir movimentos, hábitos, contatos, alterando sentido e conteúdo da autonomia das pessoas (RODOTÀ, 2004, p.95).

Em verdade os "dados pessoais são transformados em importante ativo comercial das grandes empresas de tecnologia do mundo, com o claro objetivo de obtenção de capital, além de outros até o momento não tão claros assim” (REQUIÃO, 2020, 1. 8990).

Diga-se ainda que o impacto da tecnologia na vida humana traz em seu bojo a preocupação com a liberdade, a qual não se compraz com qualquer forma de manipulação e controle. Sobre o tema, cite-se novamente Rodotà:

Embora se possa dizer que o corpo começa a ser uma máquina "nano-bio-info-neuro", por causa da concentração sobre ele de instrumentos oferecidos por essas diversas tecnologias, é preciso distinguir entre o que pode contribuir para uma potencialização sua e o que torna possíveis controles cada vez mais intensos; entre as decisões que se esgotam na esfera do interessado e aquelas que incidem sobre a vida dos outros; entre

\footnotetext{
${ }^{2}$ A comodificação é um termo que remonta às comodities que são aqueles produtos que funcionam como matériaprima e produzidos em larga escala, como, por exemplo, petróleo, café, soja, entre outros. Para Bauman, em seu livro Vida para consumo, o ser humano, na sociedade de consumo, passa ele próprio também a ser um produto, uma commodity, devendo ser torna vendável. É a chamada comidificação do ser humano.
} 
as ofertas que ampliam o poder de fazer escolhas livres e informadas e aquelas que incidem sobre a pessoa, transformando-a em um gadget.

$\mathrm{E}$ assim, enquanto se continua a insistir justamente na centralidade adquirida pelo corpo nas nossas organizações sociais e no discurso público, também se deve refletir seriamente sobre o fato de que a construção da identidade das pessoas sempre é mais intensamente confiada a algoritmos que definem as suas características e identificam as suas dinâmicas futuras (RODOTÀ, 2011, n.p).

Partindo do ensinamento de Bying-Chul Han, Alexander Perazo e Raphaella Prado relatam a existência de uma dominação do indivíduo, "em um cenário em que a ilusão da liberdade é predominante e a comunicação ilimitada representa um controle silencioso e uma vigilância absoluta que ganha força espontaneamente sem exercer qualquer constrangimento, sendo esse mecanismo chamado de psicopolítica digital" (CARVALHO; SOUSA, 2019, p. 299).

Rodotà se preocupa muitíssimo com a captação indevida e a manipulação de dados. Fazendo referência ao caso Snowden, cita a reação mundial ao esquema de monitoramento de mensagens privadas levado a efeito pelos Estados Unidos. Salienta que, naquela oportunidade, fora honrada a privacidade e a proteção dos dados da pessoa, que havia morrido "justamente para legitimar qualquer coleta de informações pessoais, reduzindo as pessoas ao papel de fornecedores obrigados de dados considerados necessários para o funcionamento do mercado e de mecanismos totalizantes de controle" (RODOTÀ, 2013a, n.p).

Assim, a proteção dos dados da pessoa é aspecto essencial do ordenamento jurídico, sendo certo que "a unidade da pessoa somente poder ser reconstituída estendendo ao corpo eletrônico o sistema de garantias elaborado para o corpo físico" (RODOTÀ, 2004, p. 106).

Rodotà inclusive propõe que a proteção de dados pessoais seja considerada um direito fundamental, apartado do direito à privacidade. Confira-se:

El problema no es solo el de una persona que quiere proteger de interferencias externas una cerrada esfera privada. El problema estriba en no confiar exclusivamente la construcción de nuestra persona a otros que quieren organizar nuestros datos según sus propios fines, expropiándonos del derecho a mantener el control sobre este nuevo cuerpo. El reconocimiento de la protección de datos como derecho fundamental cumple con el objetivo de mantener la relación entre la persona y su cuerpo, ya no enclaustrado en los confines de la fisicidad y en el secreto de lo psíquico, sino realmente dislocado, entregado a los infinitos bancos de datos que dicen al mundo quiénes somos. El hecho de que otros posean legítimamente una cuota mayor o menor de nuestros datos no les concede el poder de disponer de ellos libremente. La soberanía sobre el cuerpo se concreta en el derecho a acceder a los propios datos, estén donde estén, en exigir para ellos un tratamiento conforme a algunos principios (necesidad, finalidad, pertenencia, proporcionalidad), en poder obtener su 
rectificación, su cancelación, su integración. El cuerpo electrónico y su gestión pertenecen a la esfera jurídica de la persona (RODOTÀ, 2014, p. 151).

No mesmo sentido, em recente artigo, Clara Iglesias e Danilo Doneda manifestam que o "direito à proteção de dados compreende, como um de seus elementos principais, o estabelecimento de instrumentos que visem a reduzir o risco aos cidadãos que o tratamento de seus dados pode lhe causar" (DONEDA; KELLER, 2020, n.p).

Complementam dizendo que, para tanto, deve-se "impedir que dados pessoais sejam tratados sem que haja um objetivo consistente e fundamentado" e mesmo quando haja fundamentação, "este tratamento deve ser reduzido ao mínimo necessário para que o seu objetivo seja alcançado, além de ser proporcional aos interesses e direitos envolvidos“ (DONEDA; KELLER, 2020, n.p).

No que toca ao conceito de privacidade, interessante observar que a clássica noção de "ser deixado sozinho" tem perdido força, tendo o conceito passado a gravitar sobre a "possibilidade de cada um controlar as informações que lhe dizem respeito" (RODOTÀ, 2008, p. 26).

Assim, a ideia de privacidade, no contexto mais atual, se encontra vinculada, entre outros aspectos, "a possibilidade dos indivíduos e grupos controlarem o exercício dos poderes baseados na disponibilização de informações, concorrendo assim, para estabelecer equilíbrios sócio-políticos mais adequados" (RODOTÀ, 2008, p. 26).

Em excelente livro, dedicado "à memória de Stefano Rodotà, Danilo Doneda ${ }^{3}$ fala sobre sociedade da informação e privacidade:

[...] a proteção da privacidade na sociedade da informação, a partir da proteção de dados pessoais, avança sobre terrenos outrora improponíveis e nos induz a pensá-la como um elemento que, mais do que garantir o isolamento ou a tranquilidade, serve a proporcionar ao indivíduo os meios necessários à construção e consolidação de uma esfera privada própria, dentro de um paradigma de vida em relação e sob o signo da solidariedade - isto é, de forma que a tutela da privacidade cumpra um papel positivo para o potencial de comunicação e relacionamentos do indivíduo. Tal função interessa à personalidade como um todo e ganha importância ainda maior quando fatores como

\footnotetext{
${ }^{3}$ Danilo Doneda representará a Câmara dos Deputados no Conselho Nacional de Proteção de Danos Pessoais e Privacidade: "O professor, especialista em privacidade e proteção de dados e advogado Danilo Doneda foi indicado nesta quarta-feira, 15, como o representante da Câmara dos Deputados no Conselho Nacional de Proteção de Dados Pessoais e Privacidade, órgão consultivo da Autoridade Nacional de Proteção de Dados (ANPD), previsto na Lei 13.853/2019. A indicação de Doneda foi publicada no Diário Oficial da Câmara dos Deputados”. URUPÁ, M. Danilo Doneda representará a Câmara dos Deputados no Conselho Nacional da ANPD. 2019. Disponível em: https://www.mobiletime.com.br/noticias/ 17/10/2019/danilo-doneda-representara-a-camara-dos-deputados-noconselhonacional-da-anpd/. Acesso em: 29/6/2020.
} 
a vida em relação e as escolhas pessoais entram em jogo - como ocorre nas relações privadas, na utilização das novas tecnologias, no caso da política e, paradoxalmente, na própria vida pública (DONEDA, 2019, p. 36).

Como visto, o advento dos sistemas informatizados colocou em relevo a necessária segurança dos respectivos dados. Nesse sentido, a Europa, desde os anos setenta, tem tentado regular, através de legislação, temas relacionados ao controle dos dados pessoais e da preservação da privacidade dos indivíduos. Infelizmente, o escopo do presente trabalho não nos permite um maior aprofundamento do tema.

A seguir, analisar-se-á as imbricações entre o direito à saúde e a privacidade, no contexto da Covid-19.

\section{A COVID-19, o CORPO ELETRÔNICO E A PRIVACIDADE}

Discorrer sobre a pandemia é um grande desafio! Nas palavras de Boaventura de Sousa Santos "escrever sobre ela é pôr as nossas categorias e a nossa linguagem à beira do abismo". Isso porque o mundo pandêmico, nas palavras do citado autor, atribui "à realidade uma liberdade caótica" (SANTOS, 2020, p. 13).

Na data de hoje, o Brasil conta com 4.495.183 de casos confirmados, registrando-se a lamentável marca de 135.73 óbitos confirmados (MINISTÉRIO DA SAÚDE, 2020). Os números, por si só, demostram a gravidade atroz da doença.

Diga-se que a pandemia surpreendeu gestores brasileiros, tendo em vista que, historicamente, nunca houve real prioridade do poder público, em todas as suas esferas, quanto ao sistema público de saúde, sendo fato notório as péssimas condições do atendimento primário, o qual deveria ser responsável pelas ações voltadas à prevenção dos riscos e à promoção da saúde ${ }^{4}$.

Já o atendimento secundário e terciário, que envolvem todo o aparato referente ao tratamento de pacientes já doentes, não trilham melhor caminho. São inúmeros os relatos de hospitais lotados e mal aparelhados, falta de testes suficientes para o diagnóstico da doença, falta de corpo técnico qualificado para o tratamento da doença, ausência de insumos básicos

\footnotetext{
${ }^{4}$ Há 3 níveis de atenção à saúde, de acordo com a Organização Mundial da Saúde. O nível primário se volta aos atendimentos de grau de complexidade baixo. O foco está em consulta e exames básicos. Já o nível secundário, encampa as unidades e pronto atendimento (UPA) e presta consultas específicas como nefrologistas, cardiologistas e clínicos gerais. O nível terciário é prestado nos grandes hospitais. Presta atendimentos de emergência e cuida de procedimentos eletivos. Informações recolhidas no portal https://cmtecnologia.com.br/blog/niveis-de-atencao-asaude-e-estrategias-de-gestao/. Disponível em: 18 de jun. de 2020.
} 
para o cuidado dos doentes e mesmo ausência de equipamentos de proteção individual para as equipes médicas.

É nesse contexto que se busca enfrentar essa doença. Trata-se de uma verdadeira “operação de guerra”. Tanto que líderes mundiais afirmam, com convicção, que se vive uma crise global, sem precedentes, sendo talvez a maior crise global desde a Segunda Guerra Mundial (CARBAJOSA, 2020).

Diga-se que o isolamento social tem se mostrado o caminho mais eficaz para se evitar o contágio. Especialistas advertem que o tempo mínimo de isolamento social, para que se comece a debelar o vírus é de, pelo menos, dois meses (GIRARDI; JANSEN, 2020).

Entretanto, a população brasileira, infelizmente, mostrou-se altamente indisciplinada quanto ao tema, o que fez o vírus se espraiar por todo o país, ocasionando, como dito, um número acentuado de mortes.

Há quem justifique o comportamento do brasileiro apontando a falta de solidariedade. Outros afirmam a premência das necessidades econômicas. Sobre esses aspectos, colha-se a seguinte anotação doutrinária:

Para a mentalidade reinante na sociedade capitalista e de consumo, que erigiu como
valor máximo o ter e não o ser, a futilidade e não a utilidade, o individualismo em
lugar da solidariedade é bem difícil eleger medida de prevenção centrada,
preponderantemente, na proteção do direito à saúde, como é o caso do distanciamento
ou isolamento social. Solução que permite evitar-se o colapso do sistema de saúde,
assegurando o acesso de maior número de pessoas ao tratamento. Neste tipo de
sociedade priorizam-se as transações comerciais, as finanças, em detrimento de
direitos fundamentais, impedindo a solidariedade entre as pessoas. Assim, guiados por
esses anseios, fecham-se os olhos para o que aconteceu em países que se descuidaram
do isolamento social e o flexibilizaram, levando ao limite o atendimento médico e
hospitalar, obstando o acesso de todos os que precisam, obrigando os profissionais de
saúde a escolhas tenebrosas, sobre quem deve morrer e quem deve viver. Neste ponto
tem se revelado o traço mais perverso e cruel do ser humano, muitos encaram com
frieza tal escolha e sustentam com a tranquilidade, que os jovens devem ser
privilegiados em detrimento dos idosos (NASSAR, 2020, p. 175).

Além dos esperados impactos no mundo da saúde, já citados, a pandemia teve intensas repercussões na vida cotidiana das pessoas, tendo acarretado agravos econômicos e sociais incalculáveis.

Com efeito, a economia entrou em estado de alerta. As previsões de retração econômica mostraram-se chocantes e os governos tiveram que intervir nos mercados de forma não antes vista nas últimas décadas, sob pena de que os países mergulhassem em período de recessão econômica, sem precedentes na história recente. 
Nessa esteira, além das medidas sanitárias e de tratamento dos infectados, os governos mundiais realizaram intensos aportes financeiros na economia, quer para socorrer empresas que se viram impossibilitadas de operar, quer para ajudar os cidadãos, que se viram sem renda para suas necessidades básicas.

No que toca ao mundo do trabalho, esse foi atingido "em cheio" pela crise sanitária, sem precedentes. Empreendimentos encerraram suas atividades no mundo todo, ocasionando desemprego em massa. Também ficou evidente o grande número de trabalhadores informais, que, com a pandemia, se viram privados de condições básicas de renda. A crise econômica eclodiu aos olhos de todos, expondo as chagas sociais do país.

Medidas de isolamento social foram implementadas, muitas vezes estabelecendo um verdadeiro Estado de vigilância, onde os passos dos cidadãos passaram a ser monitorados, diuturnamente, sob o pálio da necessária contenção do vírus.

Diga-se que, em muitas situações, não se prestou a necessária informação aos cidadãos e não se buscou a chancela de poderes constituídos, como, por exemplo, o Parlamento.

Com efeito, pululam relatos de práticas absurdas no que toca ao monitoramento das pessoas, com vistas a identificar possíveis agentes de contaminação. Cite-se sobre o tema, a doutrina de Maurício Requião:

Correm as notícias das mais diversas práticas de monitoramento para tentar identificar e isolar infectados com o novo vírus, realizadas em diversos países. Na China, ponto inicial da pandemia, são utilizados drones, tecnologia de reconhecimento facial, scanners infravermelhos, além da implementação de aplicativo para classificar as pessoas de acordo com o risco de contágio, sendo tal informação transmitida para as autoridades (REQUIÃO, 2020, 1. 9029).

Sabe-se que "vasta maioria dos sistemas é uma variação do mesmo tema: usar dados de geolocalização produzidos por smartphones para determinar a adesão ao isolamento social e prever para onde a doença pode caminhar" (ROMANI, 2020, n.p).

Pode também ocorrer das informações serem "cruzadas com dados de saúde, de crédito, de redes sociais e até de câmeras do sistema de transporte" (ROMANI, 2020, n.p).

Há que dizer, entretanto, como nos adverte Bauman, que "grande parte das informações pessoais vigorosamente absorvida pelas organizações é, na verdade, disponibilizada por pessoas que usam telefones celulares, compram em shoppings, viajam de férias, divertem-se ou surfam na internet", ao que conclui: "Passamos nossos cartões, repetimos 
nossos códigos postais e mostramos nossas identidades de forma rotineira, automática, espontânea” (BAUMAN; LYON, 2004, 1. 212).

Diga-se que "A sensibilidade aos riscos políticos ligados aos registros de massa vai bem além da classe média realmente, visto que a possibilidade de discriminação atinge sobretudo as diferentes minorias e os que pertencem à classe operária" (RODOTÀ, 2008, p. 30).

Desse modo, entende-se que "a invocação da privacidade supera o tradicional quadro individualista e dilata-se em uma dimensão coletiva, uma vez que não em conta o interesse do indivíduo enquanto tal, mas como pertencente a um grupo social“" (RODOTÀ, 2008, p. 30). Assim, a discussão sobre privacidade tem se pautado na "emersão do momento coletivo e do seu aspecto ligado ao poder" (RODOTÀ, 2008, p. 31).

É por esse aspecto que se deve "ser garantido o máximo de opacidade às informações suscetíveis de originar práticas discriminatórias e o máximo de transparência àquelas que, referindo-se à esfera econômica dos sujeitos, concorrem para embasar decisões de relevância coletiva" (RODOTÀ, 2008, p. 35).

Diga-se ainda que o medo da discriminação é fator que deve ser observado na coleta de dados sensíveis dos cidadãos, especialmente tendo em vista a possibilidade de utilização dessas informações, posteriormente, para outros fins.

Nesse sentido, faz-se interessante observar como sistema de monitoramento da Coréia do Sul acabou tendo impactos discriminatórios sobre pessoas da comunidade LGBT+:

\footnotetext{
Depois que mais de cem casos de contaminação pelo novo coronavírus foram rastreados até em casas noturnas de Itaewon, bairro da capital Seul, um homem de 29 anos que testou positivo para a Covid-19 foi identificado como possível responsável pelo surto. Veículos da imprensa que cobriram o ocorrido deram grande ênfase à sua orientação sexual, relatando que ele teria visitado apenas ambientes populares entre homens gays - o que, somado a outras informações reveladas, permitiu a identificação do homem. Depois de a história circular amplamente na mídia, as redes sociais foram tomadas por manifestações homofóbicas e mensagens que o culpavam - e a comunidade LGBTI+, mais amplamente - como responsáveis pela disseminação do vírus e por colocar em risco os esforços do país no sentido de conter o avanço da doença. Há diversos relatos de membros da comunidade afirmando terem recebido ameaças, inclusive via aplicativos de relacionamento como o Grindr, direcionado a homens gays. Além de incitar ao ódio e à violência contra LGBTI+s, a exposição de membros da comunidade colocou em risco a própria efetividade da estratégia coreana de combate ao coronavírus, considerando que muitos LGBTI+s passaram a evitar a testagem por receio de exposição. Esse mesmo receio já foi também identificado no Japão, onde LGBTI+s afirmam preocupar-se com o risco de exposição pública decorrente da política de rastreamento de contato, igualmente evitando a testagem para o novo coronavírus (PICCELL; OLIVA, 2020, n.p).
} 
Também na China, o monitoramento de possíveis infectados, acabou por discriminar imigrantes de países africanos:

Em Guangdong, na China, autoridades anunciaram que todos os estrangeiros deveriam aceitar as medidas de prevenção e contenção da Covid-19, incluindo testagem e quarentena. $\mathrm{Na}$ prática, contudo, as autoridades tiveram como alvo africanos vivendo na província, realizando testagem e quarentena forçadas. Eles foram abordados em casa pela polícia, onde foram testados e receberam ordens de permanecer em isolamento, com câmeras de vigilância ou alarmes instalados fora de seus apartamentos. Não havia evidências, no entanto, para tal abordagem: a maioria dos casos de Covid-19 importados pela província envolvia cidadãos chineses retornando do exterior. Muitos dos residentes africanos abordados já havia, àquela altura, testado negativo para o coronavírus, não possuíam histórico recente de viagens ou contato com pessoas que testaram positivo para a doença (PICCELL; OLIVA, 2020, n.p).

Segundo informações do portal BBC News, no México, a Uber suspendeu as contas de dois de seus motoristas, bem como de 240 clientes, após tomar conhecimento de que um passageiro chinês, que tomara os veículos dos motoristas, tinha desenvolvido a Covid-19. A Uber se utilizara do seu banco de dados para rastrear os clientes que tinham tomado os carros onde o chinês fora transportado (BBC NEWS, 2020).

Há também relatos impactantes de que, na Índia, a transmissão do Coronavírus foi atribuída à comunidade muçulmana, que é o maior grupo minoritário naquele país de maioria hindu - e que já sofre de histórica discriminação, funcionando na atual crise sanitária como verdadeiro bote expiatório (YASIR, 2020).

Sobre a exposição indevida de dados pessoais, interessante o seguinte apontamento:

A pessoa que teve sua intimidade exposta pode sofrer de diferentes formas, a depender do contexto onde vive e das normas sociais de seu meio. A crença, o posicionamento político-partidário, a origem e até mesmo a profissão são informações que comumente são ocultadas por pessoas por medo de discriminação e por temer pela própria vida. O medo do terror extremista nos Estados Unidos e na Europa pode fazer com que uma pessoa praticante da fé islâmica seja ofendida simplesmente por praticar aquele credo, assim como praticantes de religiões de matriz africana já sofrem no Brasil as chamadas "quebras" dos terreiros, ou os judeus do terceiro Reich. Nesse ponto, transitasse entre intimidade e a vida familiar, já que uma ofensa neste sentido pode afetar não tão-somente o indivíduo como aqueles outros mais próximos do convívio (PEIXOTO, 2017, p. 84).

É importante observar, como propõe Harari, que esse estado de vigilância tem novos contornos, sendo bem mais insidioso, posto que busca dados relativos à biometria:

Se pode argumentar que não há nada novo nisso tudo. Nos últimos anos, tanto os governos como as corporações utilizaram tecnologias cada vez mais sofisticadas para 
rastrear, vigiar e manipular as pessoas. No entanto, se não somos cuidadosos, a epidemia poderia marcar um feito importante na história da vigilância. Não somente porque poderia normalizar o uso de instrumentos de vigilância massiva em países que até hoje os rechaçaram, mas ainda mais porque significa uma transição dramática da vigilância "sobre a pele" à vigilância "sob a pele".

Até agora, quando se tocava com o dedo a tela de um smartphone e se dava um clique em um link, o governo queria saber exatamente onde se havia dado o clique. Porém, com o coronavírus, o interesse central mudou. Hoje o governo quer saber a temperatura do dedo e a pressão arterial sob a pele (HARARI, 2020b, n.p) .

Ora, ao coletar dados under the skin (sob a pele) o destinatário das informações pode associar estados de temperatura, pressão sanguínea e batimentos cardíacos a estados emocionais. Poderá assim, perceber quando determinada pessoa está triste, alegre ou tem interesse em determinado assunto. Este seria um caminho aberto para manipulação, como, por exemplo, oferecimento de produtos. Também pode-se cogitar dos dados serem utilizados para discriminar certos grupos de interesse (HARARI, 2020b).

Diga-se que Rodotà, em 2004, já manifestava preocupação com o “[...] uso cada vez mais maciço de dados biométricos, principalmente de impressões digitais, possibilitando assim a realização de controles generalizados em todos os cidadãos" ao que exemplificava: "Impressões digitais, geometria da mão ou dos dedos, da orelha, íris, retina, traços faciais, odores, voz, assinatura, uso de teclado, andar, DNA” (RODOTÀ, 2004, p. 92).

Ao que concluía "o nexo entre corpo, informações pessoais e controle social pode assumir contornos dramáticos, a ponto de fazer evocar de imediato o respeito à dignidade da pessoa, o que impõem uma interpretação particularmente rigorosa do princípio da estrita necessidade na coleta e no trato de dados pessoais" (RODOTÀ, 2004, p. 97).

No Brasil, infelizmente, também foram adotadas medidas de caráter autoritário, invasivo ou pouco transparentes para o atual cenário pandêmico. Nesse sentido, condena-se a Medida Provisória n. ${ }^{\circ} 954^{5}$, de 17 de abril 2020, que determinava que empresas de telefonia disponibilizassem ao Instituto Brasileiro de Geografia e Estatística (IBGE) dados de seus clientes, tais como nome, número de telefone e endereço.

\footnotetext{
${ }^{5}$ Dispõe sobre o compartilhamento de dados por empresas de telecomunicações prestadoras de Serviço Telefônico Fixo Comutado e de Serviço Móvel Pessoal com a Fundação Instituto Brasileiro de Geografia e Estatística, para fins de suporte à produção estatística oficial durante a situação de emergência de saúde pública de importância internacional decorrente do coronavírus (covid-19), de que trata a Lei no 13.979, de 6 de fevereiro de 2020.
} 
O referido ato normativo foi retirado do ordenamento jurídico, em caráter liminar, nos autos da Ação direta de Inconstitucionalidade n. ${ }^{\circ}$ 6.387, tendo a decisão sido vazada nos seguintes termos:

\begin{abstract}
De outra parte, o art. $3 .^{\circ}$, I e II, da MP n. 954/2020 dispõe que os dados compartilhados "terão caráter sigiloso" e "serão utilizados exclusivamente para a finalidade prevista no $\S 1 .^{\circ}$ do art. $2^{\circ}$ ", e o art. $3 .^{\circ}, \S 1 .^{\circ}$, veda ao IBGE compartilhar os dados disponibilizados com outros entes, públicos ou privados. Nada obstante, a MP n. 954/2020 não apresenta mecanismo técnico ou administrativo apto a proteger os dados pessoais de acessos não autorizados, vazamentos acidentais ou utilização indevida, seja na sua transmissão, seja no seu tratamento. Limita-se a delegar a ato do Presidente da Fundação IBGE o procedimento para compartilhamento dos dados, sem oferecer proteção suficiente aos relevantes direitos fundamentais em jogo. Enfatizo: ao não prever exigência alguma quanto a mecanismos e procedimentos para assegurar o sigilo, a higidez e, quando o caso, o anonimato dos dados compartilhados, a MP $\mathrm{n}$. 954/2020 não satisfaz as exigências que exsurgem do texto constitucional no tocante à efetiva proteção de direitos fundamentais dos brasileiros (SUPREMO TRIBUNAL FEDERAL, 2020a , p. 10; 12).
\end{abstract}

Em palestra proferida no Rio de Janeiro, em março de 2003, o ex-presidente da Autoridade de Proteção de Dados Pessoas da Itália — Rodotà, então com 70 anos — já chamava a atenção da necessidade de que o mundo virtual seja um "espaço constitucional rico de garantias adequadas", sob pena de prevalecer, no meio virtual, a lógica do mercado, "já que a maioria das atividades online são do tipo comercial e que a Web é considerada uma gigantesca mina de dados pessoais, graças aos quais nasceu uma sociedade da vigilância e da classificação" (RODOTÀ, 2003, p. 10).

Importante observar que grande parte das medidas governamentais citadas são impostas na perspectiva do medo ou sob o álibi da urgência. Propõe-se para a sociedade uma falsa opção a ser feita: opta-se pela saúde ou pela privacidade?

Rodotà, discorrendo sobre o direito à verdade, coloca luz nessas falsas opções que são apresentadas aos cidadãos: "A verdade é continuamente posta à prova, imersa em uma série de conflitos: memória ou esquecimento; transparência ou privacidade; livre construção da personalidade ou subordinação a controles; identidade inclusiva ou excludente" (RODOTÀ, 2013b, p. 12).

Passa a concluir, lançando certeira crítica contra essa lógica binária “cujas alternativas seriam somente escolher um sim ou um não, sem qualquer possibilidade de individuar ponto de conjunção, de constituir relações sociais que seriam laceradas se se escolhesse somente por meio de uma abstrata atitude isolada" (RODOTÀ, 2013b, p. 12). 
Não há, entretanto, que se fazer qualquer opção. Governos democráticos têm que garantir à sua população ambos os direitos, não se podendo cogitar em restrições não razoáveis a direitos fundamentais do cidadão, como no caso, privilegiar somente a saúde em detrimento da privacidade das pessoas.

Em verdade, "proteção de dados e utilização do seu tratamento para fins de proteção sanitária para a coletividade não são inteiramente incompatíveis e não precisam ser considerados dentro de uma lógica de exclusão (perde x ganha), podendo coexistir desde que observados certos princípios” (MODESTO; EHRHARDT JUNIOR, 2020, p. 149).

Questionado se depois da pandemia os países seriam mais manipuláveis, caindo em autoritarismos ou populismos, o filósofo sul-coreano Byung-Chul Han brinca dizendo que o vírus não apoia a democracia. Argumenta alfim que os regimes autoritários se alimentam do medo, promovendo, por conta da pandemia, regimes de exceção. Esse seria o fim da democracia (HAN, 2020).

Interessante observar, no que toca à privacidade, que a já citada Lei n. ${ }^{\circ} 13.979^{6}$, de fevereiro de 2020, ao dispor sobre medidas de enfrentamento ao Coronavírus, em seu art. $6^{\circ}$, tornou "obrigatório o compartilhamento entre órgãos e entidades da administração pública federal, estadual, distrital e municipal de dados essenciais à identificação de pessoas infectadas e com suspeita de infecção pelo coronavírus, com a finalidade exclusiva de evitar a propagação" (BRASIL, 2020b, n.p).

Por outro lado, a já citada LGPD classifica, em seu art. $5^{\circ}$, as informações relativas à saúde da população como dados ditos "sensíveis", que são aqueles dados pessoais "sobre origem racial ou étnica, convicção religiosa, opinião política, filiação a sindicato ou a organização de caráter religioso, filosófico ou político, dado referente à saúde ou à vida sexual, dado genético ou biométrico, quando vinculado a uma pessoa natural" (BRASIL, 2020a, n.p).

A mesma LGPD, em seu art. 11, prevê, no inciso I, que o tratamento de dados sensíveis somente poderá ocorrer quando o titular dos dados der o seu consentimento. Diga-se ainda que o tratamento, sem o consentimento do titular, é exceção, podendo ocorrer somente nas hipóteses previstas na própria LGPD (art. 11, II).

\footnotetext{
${ }^{6}$ Dispõe sobre as medidas para enfrentamento da emergência de saúde pública de importância internacional decorrente do coronavírus responsável pelo surto de 2019.
} 
Ainda sobre dados sensíveis, colha-se o ensinamento de Peixoto (2017, p. 93): “dados pessoais que podem, caso ocorra algum tipo de violação deles, causar algum tipo de discriminação, afetar o modo de vida pessoal de quem foi exposto, como, por exemplo, dados sobre a religião da pessoa, as escolhas morais e filosóficas desta, ser portador de certos tipos de enfermidades, etc".

Ora, muito embora a LGPD não estivesse em pleno vigor em fevereiro de 2020 quando da promulgação da citada Lei 13.979, de 2020 - questiona-se se o compartilhamento obrigatório de dados pessoais plasmado nesta última lei, seria compatível com os dispositivos da LGPD, posto que: (i) não existe anuência do cidadão; (ii) não se garante a anonimização dos dados informados; e (iii) não se deixa claro quais seriam os "dados essenciais".

Sobre o tema, tem razão o jurista alagoano Marcos Ehrhardt Júnior, ao pontificar que, independentemente da entrada em vigor da LGPD, a citada obrigatoriedade encontraria óbice na Constituição e no Marco Civil da Internet. Confira-se:

\begin{abstract}
Mesmo sem a LGPD estar em vigor, é possível fundamentar a necessidade de proteção dos dados pessoais, na proteção conferida à intimidade e à vida privada das pessoas, consagrada no inciso $\mathrm{X}$ do art. 5. ${ }^{\circ}$ da Constituição Federal e reiterada no art. 21 do Código Civil, que assegura sua inviolabilidade e a possibilidade de se buscar tutela inibitória quando necessário.
\end{abstract}

Junte-se a isso a incidência do Marco Civil da Internet (Lei 12.965/14), para situações em que a coleta de dados ocorrer mediante utilização da rede mundial de computadores, pois entre os seus princípios encontramos a proteção da privacidade e a proteção dos dados pessoais (art. $3^{\circ}$ ), com a possibilidade de responsabilização dos agentes de acordo com suas atividades (EHRHARDT JÚNIOR; SILVA, 2020, n.p) .

Importante ressaltar ainda a preocupação do professor Maurício Requião com o "póspandemia”. O autor relata desconforto com a possibilidade de que os dados coletados durante este período excepcional sejam posteriormente utilizados para fins inconfessáveis:

\footnotetext{
Não pode essa grave crise mundial servir como justificativa para montar um sistema de vigilância e monitoramento, por parte de empresas e governos, ainda mais severo sobre os cidadãos. A preocupação sobre como se dará o uso desses dados e dos sistemas de tratamento no futuro se agrava, principalmente, quando se pensa em governos que tendem ao autoritarismo. Esta excepcional capacidade de monitoramento, somada a poderes especiais que têm sido dados a governantes em alguns países, inclusive em prejuízo da democracia (REQUIÃO, 2020, 1. 9276).
}

Ainda no que toca ao uso de medidas tecnológicas para o combate ao Coronavírus, Ehrhardt Júnior pugna por uma saída intermediária, manifestando, entretanto, preocupação, assim como Requião, com a possibilidade de uso indevido ulterior dos dados coletados: 
A admissão de tais medidas como ferramenta para o salvamento de vidas não pode ser afastada, máxime no panorama de extrema incerteza em que a pandemia se situa e do elevado número de mortes já ocasionadas em razão do vírus. Deixar as tecnologias que temos inutilizadas em face de uma situação de calamidade pública parece não fazer muito sentido.

O mais importante é que não nos esqueçamos de impor balizas a essas medidas, seja em termos de duração, seja em termos de supervisão legal e utilização de modo uniforme das informações coletadas, para que posteriormente tais dados não sejam utilizados com outros fins e a situação de emergência não nos faça recair em posterior excesso.

Torna-se crucial, então, definir parâmetros de transparência, principalmente quando da ocasião do envolvimento de empresas privadas do ramo tecnológico, que podem ver a oportunidade de, com espeque no argumento de eventuais avanços no combate ao vírus por meio do tratamento de dados, beneficiar-se nessa atividade num futuro próximo, sem possibilidade de se sindicar precisamente quais informações foram fornecidas durante o combate à pandemia (EHRHARDT JÚNIOR; SILVA, 2020, n.p).

Por fim, mais uma vez, inspira-se em Rodotà que, em sua obra, dá ênfase ao conceito de "pessoa" - núcleo para a concretização de direitos fundamentais — razão pela qual, no que toca à reflexão sobre o eventual embate entre privacidade e saúde se faz necessário que a “atenção jurídica se volte a dados que expressam uma nova realidade, como, por exemplo, "o consentimento informado, a integridade da pessoa e sua irredutibilidade ao mercado" (RODOTÀ, 2014, p. 154).

\section{CONSIDERAÇÕES FINAIS}

Rodotà, em artigo publicado em 2007, já se preocupava com a criação de uma sociedade de vigilância, "na qual um número crescente de pessoas fosse 'etiquetado' para ser constantemente vigiado, e o corpo humano fosse assemelhado a qualquer objeto em movimento, controlável à distância com uma tecnologia de satélite, ou então, pela utilização de frequências radiofônicas" (RODOTÀ, 2007, n.p).

No texto, o autor italiano manifesta profunda preocupação com mudanças que impliquem "o abandono do respeito à dignidade e, por conseguinte, da humanidade de cada pessoa“ (RODOTÀ, 2007, n.p).

Desse modo, mesmo nesse cenário de combate ao novo Coronavírus os estudiosos, juristas, os profissionais de saúde e os agentes governamentais devem ponderar acerca da necessidade e conveniência da coleta de dados da população, especialmente a "utilização de 
dados biométricos", não se devendo pautar somente em um estudo de "custo-benefício" mas sim na valorização da "liberdade pessoal, integridade e dignidade" (RODOTÀ, 2004, p. 98).

Questionado sobre o aprendizado com toda a crise do novo Coronavírus, Harari sobreleva o valor de "informações científicas confiáveis" ao que pondera: "quando um país sofre uma epidemia, deve estar disposto a compartilhar as informações sobre o surto com sinceridade e sem medo da catástrofe econômica, enquanto que outros países devem poder confiar nessas informações e ajudar a vítima ao invés de repudiá-la” (HARARI, 2020a , n.p).

Como se vê, Harari sugere que a informação seja democraticamente compartilhada entre os povos, sem que haja escamoteamento da verdade, ou das finalidades subjacentes ao ato de compartilhar e receber informações.

Defende-se que isso também seja aplicável no contexto do compartilhamento de informações entre os cidadãos e o poder público. Não pode pairar dúvidas sobre as reais intenções do compartilhamento de dados sensíveis, especialmente, no que toca à preservação da privacidade das pessoas, a qual deve ser observada inclusive em casos de emergência de saúde.

Enfim, a Covid-19 trouxe profundas mudanças na sociabilidade humana. Fala-se da antecipação de aproximadamente cinco anos no curso da história. Nesse contexto, o poder público e a sociedade, em todo o mundo, acabaram, bem ou mal, se organizado para dar respostas à praga que nos assola. Muitas destas respostas implicaram discussões públicas e a elaboração de normas jurídicas, que lhes vieram respaldar, como ocorrera aqui no Brasil.

Entretanto, como asseverado, governos, de forma ardilosa, tentam aproveitar o caos pandêmico para impingir a seus cidadãos retrocessos em seus direitos fundamentais. Os exemplos são vários: vigilância austera e desmedida, coleta inadvertida de dados pessoais, desemprego e perda de direitos trabalhistas, ameaça de corte de remuneração de servidores públicos, hipertrofia do poder executivo sobre o legislativo e judiciário, entre tantos outros exemplos.

Os governos autocráticos, mais uma vez pedem que o povo faça uma escolha: direito à saúde ou privacidade? Retoma-se à falácia da "Escolha de Sofia"7. Seria possível fazer

\footnotetext{
${ }^{7}$ No drama de 1982, A Escolha de Sofia, do Diretor Alan J. Pakula, Meryl Streep interpreta uma mãe polonesa, acusada de contrabando, que se vê presa no campo de concentração de Auschwitz, durante a $2^{\mathrm{a}}$ Guerra mundial, juntamente com seus dois filhos pequenos, um menino e uma menina. Um sádico oficial nazista lhe obriga a salvar da execução apensas uma das crianças, sob pena das duas serem executadas. O termo "escolha de Sofia" ficou
} 
opções, ou a pandemia justificaria qualquer imposição estatal? “A crise do coronavírus poderia ser o ponto de inflexão da batalha. Quando se dá a possibilidade às pessoas de escolher entre privacidade e saúde (grifos no original), normalmente escolhem a saúde" (HARARI, 2020b, n.p).

Entretanto, a exata interpretação da realidade que se vive nos conduz a não se abdicar indevidamente de direitos que nos foram outorgados como fruto de lutas históricas. Nesse contexto, a democracia possibilita a amplificação da voz de resistência dos cidadãos, bem como sua união para fazer frente aos arroubos autoritários dos governos de plantão.

No caso específico do Brasil, o quadro se agrava posto que o próprio regime democrático tem sido objeto de constantes ataques do atual Presidente da República. Mas, alto lá recruta! A democracia é uma conquista da sociedade brasileira. Não se está disposto, conforme se percebe amplamente no seio social, a abrir mão desse patrimônio cívico coletivo.

\section{REFERÊNCIAS}

BAUMAN, Z.; LYON, D. Vigilância líquida. 1ª ed. [S.l.]: Zahar - Arquivo Kindle, 2004.

BBC NEWS. Coronavírus: Uber blocks drivers who picked up coronavirus man. BBC News online, fevereiro 2020. Disponível em: https://www.bbc.com/news/technology51358042. Acesso em: 26/6/2020.

BRASIL. Lei No 13.709, de 14 de agosto de 2018. Lei Geral de Proteção de Dados (LGPD), 2020a. Disponível em: http://www.planalto.gov.br/ccivil_03/_ato2015-2018/ 2018/lei/L13709.htm. Acesso em: 26/6/2020.

BRASIL. LEI No 13.979, DE 6 de fevereiro de 2020. Dispõe sobre as medidas para enfrentamento da emergência de saúde pública de importância internacional decorrente do coronavírus responsável pelo surto de 2019, 2020b. Disponível em: http://www.planalto.gov.br/ccivil_03/_ato2019-2022/2020/lei/L13979.htm. Acesso em: 26/6/2020.

BRASIL. Supremo Tribunal Federal. Medida Cautelar na Ação Direta de Inconstitucionalidade No 6.387 - Distrito Federal., Brasília, 2020a. Disponível em: http://portal.stf.jus.br/processos/downloadPeca.asp?id=15342959350\&ext=.pdf. Acesso em: 21/6/2020.

atrelado a situações limites, impostas de forma inadvertida, em que uma pessoa tem que tomar uma decisão capital, sob elevada pressão. Meryl Streep ganhou o Oscar de melhor atriz por sua atuação no filme. Fonte: GAÚCHAZH. Disponível em: https://gauchazh.clicrbs.com.br/geral/noticia/2015/08/o-que-significa-a-expressao-a-escolha-de sofia-usada-pelo-secretario-giovani-feltes-4822225.html. Acessado em: 22 de jun. de 2020. 
CARBAJOSA, A. Merkel apela aos cidadãos e chama coronavírus de "maior desafio desde a Segunda Guerra Mundial": Pela primeira vez em 14 anos de mandato a chanceler alemã fez um discurso televisionado para além dos tradicionais de Ano Novo para enfatizar a gravidade da doença. 2020. El país online. Disponível em: http://www.planalto.gov.br/ccivil_03/_ato2019-2022/2020/mpv/ mpv959.htm. Acesso em: 18/6/2020.

CARVALHO, A. P. N. de; SOUSA, R. P. A. de. A influência da psicopolítica digital nas contratações virtuais e seus reflexos no aumento da vulnerabilidade do consumidor. Revista de Direito do Consumidor, Editora Revista dos Tribunais, Ano 28, n. 123, p. 289-309, Maio-Junho/2019.

DONEDA, D. Da privacidade à proteção de dados pessoais: elementos da formação da Lei geral de proteção de dados. 1. ed. em e-book baseada na 2. ed impressa. ed. São Paulo: Thompson Reuters, 2019. Disponível em:

https://proview.thomsonreuters.com/title.html?redirect= true \& titleKey $=\mathrm{rt} \% 2 \mathrm{Fmonografias} \% 2 \mathrm{~F} 215543393 \% 2 \mathrm{Fv} 2.2 \&$ titleStage $=$ F\&titleAcct=i0ace3e3500000172ed126866c3d37209\#sl=p\&eid= e8b93d6ea940828c8b5479784ff9bc34\&eat=a-220623432\&pg=III\&psl=\&nvgS= false \&tmp=400. Acesso em: 29/6/2020.

DONEDA, D; KELLER, C. I. Mirando em fake news e acertando em vigilância: a identificação de usuários como estratégia falida de combate à desinformação. 2020. Jota online. Disponível em: https://www.jota.info/coberturas-especiais/liberdadedeexpressao/mirando-em-fake-news-e-acertando-em-vigilancia-24062020. Acesso em: $29 / 6 / 2020$.

EHRHARDT JÚNIOR, M.; SILVA, G. B. P. Sociedade da informação e o direito na era digital. 2010. Online. Disponível em: http://www:marcosehrhardt:adv:br/index:php/artigo/2010/06/06/sociedade-dainformacao-e-o-direito-na-era-digital. Acesso em: 29/6/2020.

EHRHARDT JÚNIOR, M.; SILVA, G. B. P. Privacidade e proteção de dados pessoais durante a pandemia da COVID-19. 2020. Portal Jusbrasil online. Disponível em: https://direitocivilbrasileiro.jusbrasil.com.br/artigos/824478175/ privacidade-e-protecao-dedados-pessoais-durante-a-pandemia-da-covid-19?ref= feed. Acesso em: 26/6/2020.

GIRARDI, G.; JANSEN, R. Para conter coronavírus, isolamento social precisa durar pelo menos dois meses. 2020. Estadão online. Disponível em:

https://saude. estadao.com.br/noticias/geral,para-conter-coronavirus-isolamentosocialprecisa-durar-ao-menos-dois-meses, 70003249866. Acesso em: 18/6/2020.

HAN, B. Filósofo coreano prevê mundo pós-Covid em "estado de guerra permanente". [Entrevista concedida a] Agência EFE. 2020. Online. Disponível em: https://jovempan.com.br/noticias/mundo/filosofo-coreano-mundo-pos-covid.html. Acesso em: $26 / 6 / 2020$. 
HARARI, Y. N. Na batalha contra o coronavírus, a humanidade carece de líderes: o antídoto contra a epidemia não é a segregação, e sim a cooperação. El País online, abril 2020a.

Disponível em: https://brasil.elpais.com/opiniao/2020-04-13/na-batalhacontra-ocoronavirus-a-humanidade-carece-de-lideres.html. Acesso em: 27/6/2020.

HARARI, Y. N. O mundo depois do coronavírus. Instituto Humanitas Unisinos online, 2020b. Disponível em: http://www.ihu.unisinos.br/78-noticias/597469-o-mundodepois-docoronavirus-artigo-de-yuval-noah-harari. Acesso em: 27/6/2020.

MINISTÉRIO DA SAÚDE. Coronavírus Brasil. 2020. Online. Disponível em: https://covid. saude.gov.br/. Acesso em: 19/9/2020.

MODESTO, J. A.; EHRHARDT JUNIOR, M. Danos colaterais em tempos de pandemia: preocupações quanto ao uso dos dados pessoais no combate a COVID-19. Revista Eletrônica de Direito e Sociedade online, Canoas, v. 8, n. 2, p. 143-161, 2020. Disponível em: http://dx.doi.org/10.18316/REDES.v8i2.6770. Acesso em: 29/6/2020.

NASSAR, R. de N. S. Direito fundamental à prevenção em tempos de coronavírus. In: BELMONTE, A. A.; MARTINEZ, L.; MARANHÃO, N. M. (org.). O Direito do Trabalho na crise da COVID-19. Salvador: Juspodivm, 2020. p. 163 - 176.

PEIXOTO, E. L. C. O conteúdo do direito da privacidade no direito brasileiro contemporâneo. 2017. 136 p. Dissertação (Mestrado em Direito) — Universidade Federal de Alagoas. Disponível em:

http://www.repositorio.ufal.br/bitstream/riufal/1986/1/O\%20conte\%c3\%bado\%20do\%20di reito $\% 20$ da $\% 20$ privacidade $\% 20$ no $\% 20$ direito $\%$

20brasileiro\%20contempor\%c3\%a2neo.pdf. Acesso em: 21/6/2020.

PICCELL, R. R.; OLIVA, T. D. Covid-19: técnicas de monitoramento e riscos a grupos vulneráveis. Justificando online, junho 2020. Disponível em:

https://www.justificando.com/2020/06/15/covid-19-tecnicas-de-monitoramento-e-riscos-agrupos-vulneraveis/. Acesso em: 27/6/2020.

REQUIÃO, M. Covid-19 e proteção de dados pessoais: o antes, o agora e o depois Arquivo Kindle. In: BAHIA, S. J. C. (coord.). Direitos e Deveres Fundamentais em Tempos de Coronavírus. 1a . ed. São Paulo: Editora IASP, 2020. p. p. 8990 - p. 9347. ISBN 978-65-87082-00-4.

RODOTÀ, S. Palestra Professor Stefano Rodotà. 2003. Online. Disponível em: http://www.rio.rj.gov.br/dlstatic/10112/151613/DLFE-4314.pdf/ GlobalizacaoeoDireito.pdf. Acesso em: 28/6/2020.

RODOTÀ, S. Transformações do Corpo (Tradução de Maria Celina Bodin de Moraes). RTDC, v. 19, p. 92 - 107, jul/set 2004. Disponível em: https://www.passeidireto.com/arquivo/4123306/stefano-rodota-transformacoes-docorpo?q= stefano $\% 20 \operatorname{rodot} \% \mathrm{C} 3 \%$ A0. Acesso em: 28/6/2020. 
RODOTÀ, S. Quando o corpo se torna ciência. O caso Pistorius e o pós-humano. Instituto Humanitas Unisinos online, julho 2007. Disponível em: http://www.ihu.unisinos.br/176noticias/noticias-2007/573872-quando-o-corpo-setorna-ciencia-o-caso-pistorius-e-o-poshumano. Acesso em: 27/6/2020.

RODOTÀ, S. A vida na sociedade da vigilância: a privacidade hoje: Parte I(Tecnologia e Direitos). Renovar, 2008. Disponível em: https://www.passeidireto.com/ arquivo/4123304/stefano-rodota-tecnologia-e-direitos-a-vida-na-sociedade-devigilancia. Acesso em: 28/6/2020.

RODOTÀ, S. Liberdade e direitos: breves instruções para o ser humano do futuro. Revista Instituto Humanitas Unisinos online, setembro 2011. Disponível em: http://www.ihu.unisinos.br/noticias/501186-liberdade-e-direitos-breves-instrucoespara-oser-humano-do-futuro. Acesso em: 27/6/2020.

RODOTÀ, S. A revolução dos direitos, de Malala ao Datagate. Instituto Humanitas Unisinos online, julho 2013a. Disponível em: http://www.ihu.unisinos.br/noticias/ 521982a-revolucao-dos-direitos-de-malala-ao-datagate-artigo-de-stefano-rodota. Acesso em: 27/6/2020.

RODOTÀ, S. O direito à verdade. 2013b. Online. Disponível em: https://www.passeidireto.com/arquivo/71110444?utm_campaign=androidarquivo\&utm_me dium=mobile. Acesso em: 28/6/2020.

RODOTÀ, S. El derecho a tener derechos. Madrid: Editorial Trotta, 2014. ISBN 978-849879-538-7.

ROMANI, P. B. Uso de dados de localização no combate à covid-19 pode ameaçar privacidade. O Estado de São Paulo, São Paulo, abril 2020. Disponível em: https://link.estadao.com.br/noticias/cultura-digital, uso-de-dados-de-localizacao-nocombatea-covid-19-pode-ameacar-privacidade,70003268063. Acesso em: 26/6/2020.

SANTOS, B. de S. A cruel pedagogia do vírus. Coimbra: Edições Almedina S.A., 2020. $32 \mathrm{p}$.

YASIR, S. Índia Is scapegoating Muslims for the spread of the Coronavirus. 2020. FP online. Disponível em: https://foreignpolicy.com/2020/04/22/india-muslimscoronavirus-scapegoat-modihindu-nationalism/. Acesso em: 26/6/2020. 